\section{B A Institute of \\ YK Business Administration \\ 六下 \\ Karachi \\ Leadership and Ideas for Tomorrow}

Business Review

Volume 7 Issue 1 January-June 2012

$1-1-2012$

\title{
Cultural context and its affect on management practices in organizations - a special focus of compensation practices
}

\author{
Shandana Shuaib \\ Institute of Management Sciences, Hayatabad, Pakistan
}

Follow this and additional works at: https://ir.iba.edu.pk/businessreview

Part of the Benefits and Compensation Commons, Business Administration, Management, and Operations Commons, and the Strategic Management Policy Commons

\section{(c) (;)}

This work is licensed under a Creative Commons Attribution 4.0 International License.

\section{Recommended Citation}

Shuaib, S. (2012). Cultural context and its affect on management practices in organizations - a special focus of compensation practices. Business Review, 7(1), 106-115. Retrieved from https://doi.org/ 10.54784/1990-6587.1305

This article is brought to you by iRepository for open access under the Creative Commons Attribution 4.0 License and is available at https://ir.iba.edu.pk/businessreview/vol7/iss1/9. For more information, please contact irepository@iba.edu.pk. 


\title{
ARTICLE
}

\section{Cultural Context and Its Affect on Management Practices in Organizations- A Special Focus of Compensation Practices}

\author{
Shandana Shuaib \\ Institute of Management Sciences, Hayatabad, Pakistan
}

\begin{abstract}
Management practices are carried out in organizations which operate in some sort of environment. The environment is basically divided into two types: internal environment and external environment. In both these environments culture constitutes the main part. Thus, in order to fully comprehend the management practices in organizations it is utmost necessary to understand the cultural context of that society in which it operates. Many management practices if enforced without taking into consideration its cultural context may not yield the expected results. Similarly a management practice which might be very effective in one culture may not be so in another cultural context and thus fail to realize its full potential or may be a total failure in some other cultural context. This is not to be assumed that the management practices are wrong or ineffective but it might just lack acclimatization of those management activities in accordance to its cultural context. The same is true for compensation practices which are one of the most important HR practices both from the perspective of employer as well as employee. If compensation practices are not aligned with the internal and external cultural context the result will be inefficiency. Hence, for management practices to be effective and efficient the first and foremost duty of managers and social experts is to understand the cultural context in which those practices are applied otherwise the result will be disappointing. This is of great significance for developing countries where many of the management practices are adopted from the west without its proper adaptation to its eastern culture resulting in discouraging results and at times utter failure for the management.
\end{abstract}

Key Words : Culture, management, high and low context cultures, individualism and collectivism, compensation.

A Malay proverb translated, means some what like this "When you enter a cow's barn, moo, and when you enter a goat's shed, bleat"(Salleh, 2005).

"Human interest in culture surely is not new. One can speculate that being able to understand people beyond one's own tribe has been at least a secondary pursuit for as long as humankind has wandered from home terrain. The systematic examination of culture as social phenomenon began in earnest with early folklorists and anthropologists "(Wheatley, 2009).

It appears that management practices which were till now considered as universal, is not true. Theoretically, we can accept the fact that management is universal but practically it differs from culture to culture. It can be simply put that the universality of the management 
concepts can be accepted but not the practices. Management practices are carried out in organizations which operate in some sort of environment. According to LeBaron \& Bruce (1993), every research is conducted in some sort of context. The context basically refers to the environment in which the variables are studied to determine their relationship. As culture is an important element of environment, it is absolute necessary to have an understanding of the culture in which the study is accomplished.

Studying management strategies and practices without linking them to its environment will yield little understanding and its enforcement will not produce the expected results. Mustafa et al (2005) urged the need to understanding cultural differences are crucial due to increased globalization. Competition has increased manifold making it obligatory for the firms to understand the environment and devise management practices in conformity with it. The environment provides the background for management practices.

The environment is basically divided into two types: internal environment and external environment, such as the environment which persists inside and outside the organization respectively. In both these environments culture constitutes as the main component. Organizational values mirror the organizational culture, which further impacts the employees' attitudes, behavior, and actions. According to LeBaron (2003) "organizational culture is made of employees' values, attitudes and beliefs, which in turn affects employees' behavior towards work and work place" (also see Kuhn, 2009). External environment affects the internal environment which further affects the management practices of an organization. Thus, in order to fully comprehend the management practices in organizations, it is utmost necessary to understand the cultural context of that organization as well as the broader societal culture in which it operates.

Similarly a management practice might be very effective in one culture but may not produce similar results in another cultural context and thus fail to realize its full potential or may be a total failure in some other cultural context. This is not to be assumed that the management practices are wrong or ineffective but it might just lack acclimatization of those management activities in accordance to its cultural context. Hence, for management practices to be effective and efficient the first and foremost duty of managers and all management and all social experts is to understand the cultural context in which those practices are applied otherwise the results will be disappointing. This is of great significance for under developing countries where many of the management practices are adopted from the developed nations in an effort to prosper over night, without proper adaptation of such practices in the host country. No wonder the results are discouraging and at times utter failure for the management.

"The importance of national culture and its influence on management theory and practice has been proved by Hofstede (1980) in his cross cultural studies of work related values" (Sokoya, 1998). Harold has also revealed in his research that Hofstede (1980) has emphasized the affect of culture not only on the thinking of the individuals in a society but the "structure and functioning of many institutions aside from the family" (Ogden et al, 1980).

Fontaine and Richardson (2003) consider it as "a cliché that the world economy is becoming increasingly global day by day and that many of the qualms the world faces spin around culture." This fact has led to increased interest in cross-cultural management but at the same time, cross-cultural management is still beleaguered by a wealth of empirical data (Redding, 1987). According to Hofstede (2001) cross-cultural issues can be observed at a national level, organizational level or individual level " (Fontaine \& Richardson, 2003) According to Hofstede (1980) when Culture's Consequences appeared in 1980's, it represented a new paradigm in social science research: analyzing survey-based values data at the national 
level and quantifying differences between national cultures by positions on these dimensions. "Like other new paradigms, the cultural paradigm initially met with rejection, criticism and ridicule next to enthusiasm" (Kuhn, 1970). The cultural paradigm inspired a number of other studies in different contexts and disciplines (Hofstede, 1980).

According to Horwitz et. al, (2006) a country's culture and business environment can cause value elements to differ significantly across national borders (Johnson et al., 1995). In a cross-cultural study examining the managerial values of accountants from four countries, it was found that the Chinese place less importance on motivation and job satisfaction than do the Dutch but Indians value it more than Americans. By contrast, Chinese value profit maximization, but accountants in other countries place it rather far down in their rankings of organizationally important values. Culture has both international and ethnic implications (Ouchi and Jaeger, 1978). They found that Japanese tend to focus more on long term, are more involved in group decision making, less likely to delegate responsibilities to an individual compared with Americans, more willing to accept a go-slow approach to career promotions, less focused on a clear career path, more comfortable with informal controls, and more concerned about the welfare of the entire organization."

\section{Cultural Context}

"In 1959, Hall published his now famous, The Silent Language, in which he postulated the idea that cultures can be typed according to certain characteristic dimensions of behavior " (Mustafa et al ,2005). "Tylor (1871) defined culture as 'that complex whole that includes knowledge, beliefs, art, laws, custom, and any other capabilities and habits acquired by man as a member of society' " (Vesa et al, 2008). Culture has been defined in many ways by different experts of the field and social scientists. Hofstede (2001) measures cultural values relating to spheres such as interpersonal relationships and hierarchies. Four dimensions of culture that helped explain the differences among the respondents emerge:

1. Uncertainty avoidance - a society's tolerance of the unpredictable; thus cultures which scored low on uncertainty avoidance index, are more comfortable with uncertainty.

2. Power distance - a society's acceptance of the unequal distribution of power; People in high power distance cultures are much more comfortable with a larger status differential than low power distance cultures.

3. Individualism/Collectivism - the extent to which the interests of the individual prevail over the interests of the group within a society; and describes the degree to which a culture relies on and has allegiance to the self or the group.

4. Masculinity/Femininity - the relative strength of masculine vs. feminine values in a society. It further refers to clear distinction of male and female roles in a society. Feminine cultures prefer equality between male and female and less prescriptive roles related to each gender.

Later, yet another dimension was added by Bond (1987) to the existing four cultural dimensions of Hofstede. This dimension refers to the long vs. short term orientation. This new dimension was meant to explain the rapid economic development of many Asian countries. This dimension was also named as "Confucian Dynamism". It promoted a particular set of ethics prevalent in the Confucian teaching. These teachings lead to economic development and include: thrift, perseverance, a sense of shame, and following a hierarchy. These dimensions have been confirmed by several other researchers around the world and the same dimensions have been used in business issues and management practices by organizations. 


\section{High/Low Context Cultures}

According to Hall (1998) high context communication is one in which most of the communication is in explicit form while very little is in coded form. A low context communication is the opposite in which mass of the information is in coded form and very little in explicit form of words. A high context culture can be differentiated from low context culture on the basis of four characteristics such as emotions in a close relationship, directness of message conveyed, use of non verbal communication, and use of digital or analogous language. Hall (1998) asserts that the high context communication involves emotions and close relationships while the low context is less personal touch is involved and is devoid of emotions, it uses more of the logical part of the brain ( Saleh, 2005).

"The second characteristics on the basis of which culture can be labeled as high or low context is indirectness, which according to Hall (1976) an individual will take around things expecting the listener to fill in the gaps in the message? Hall (1976) notes that group members in high context cultures are expected to know what is troubling the group member but this is not the case in low-context culture. Another characteristic of high-context culture is that people learn to understand others through non-verbal responses. Kitayama and Ishii (2002) assert that information in verbal content of East Asian language is relatively low so non-verbal cues provide the missing link. In low-context culture the non-verbal cues is not much significant in communication" (Salleh, 2005)

Cultural context cannot be put into two water tight compartments. No culture can be purely a high or low context but it is the degree to which the features of cultural context such as high and low contexts are more prominent in the society, that labels a particular culture as high or low context. Thus cultural context can be measured along a continuum. Usually it has been witnessed that western society has low context culture and eastern society is inclined towards high context culture.

\section{Individualism vs. Collectivism}

To further elaborate the understanding of high-context and low-context culture some of the cultural and behavioral studies experts have expressed their views from yet another perspective-i.e., individualism and collectivism. The demographics of low-context culture reflect the features of individualism and vice versa. "According to Triandis (1994); Chatman and Barsade (1995) the two most theoretically rich dimensions of cultural context used for cultural analysis and which also provide a meaningful insight into organizational cultures are individualism and collectivism" (Kuhn, 2009). Mustafa, Bhagat, \& Babakus, (2005) has shed some light on individualism versus collectivism after collecting the view point of cultural, social and behavioral experts through his cross-cultural study. He says that individualism and collectivism is not the sole measure of cultural differences, but it has been highly noteworthy in the demarcation of individual and group behavior, goal achievement, and relationship importance (Earley \& Gibson, 1998; Triandis, 2002a, 2002b). The dimension of individualism versus collectivism has been found to account for a significant amount of variance in the social behavior of individuals across cultures (Triandis, 1995). People generally do not fit at the extremes of behavior, as defined in the concept of individualism or collectivism; "people are always gray - never black or white" (Singelis, et.al., 1995: 243). "According to Hofstede (1991) individualism, taken to its extreme, is selfishness; extreme collectivism is tyranny "(Vesa, Tiina \& Hautala, 2008).

"(Triandis, 1995) has given some important defining factors in individualism and collectivism that are important when identifying differences in temporal orientation among cultures: In individualistic cultures, individuals view themselves as independent therefore, 
groups have less cohesion. The opposite is true for collectivist culture (Vesa, Tiina \& Hautala, 2008). Similarly in individualistic cultures personal goals take precedence over collective goals or group goals, whereas, in collectivistic cultures personal goals are subjugated by group goals.

Individualist pay lesser heed to relationship and they can easily move in and out of groups especially where staying in the group has less benefits and more cost. "When the costs exceed the benefits, the relationship is often dropped" (Singelis, et.al., 1995: 244). Whereas, the collectivist will give preference to relationship without caring about its costs. According to Kim, Triandis, Kagitcibasi, \& Yoon ( 1994)"Collectivists consider relationships to be essential, and tend to maintain a relationship even if the costs of maintaining it are greater than the benefits" (Mustafa, Bhagat, \& Babakus, 2005).

In collectivism culture people are strongly bonded to their group and they will try to protect their loyalty at any cost. Hofstede (1980) has identified ten differences between individualism and collectivism. The summary of these differences is that in individualist societies people are only responsible for and conscious about them selves and their immediate family members only. They prefer privacy and value up hold personal opinions and goals. Task prevails over relationship. It is simply an "I" culture. Collectivists' societies have totally opposite features. Such societies have "We" culture. Individualism prevails in developed and western countries (Hofstede 1980), while collectivism prevails in less developed and most of the Eastern countries; Japan takes a middle position on this dimension.

\section{The Role of Culture in Individual's Perception}

Culture unconsciously affects our daily lives by shaping up our beliefs, thoughts and conviction. The same is true for organizational culture. Hofstede (1980) who can be rightly considered as the father of cultural studies has described culture as "the software of mind". "Culture is the collective programming of the mind that distinguishes the members of one human group from another." The term itself is derived from a Latin root "colere", (Oxford Concise Dictionary, 2005) which means to prepare and develop. Wheatley (2009) has quoted the definition of culture given by Harris \& Moran. They have defined culture as "distinctly human means of adapting to circumstances and transmitting this coping skill and knowledge to subsequent generations".

According to Salleh (2005) globalization and workforce mobilization have provoked many researchers to demeanor intercultural studies. Culture plays a big role in the development of human thoughts and behavior. Ignoring cultural differences in an interaction can potentially signal trouble. Companies that overlook the salient features of culture find themselves in trouble. Mustafa, Bhagat, and Babakus (2005) in a cross cultural investigation of polychronicity quotes the definitions of Trompenaars (1994) that "culture is the consequence of finding way out to problems with the environment, time, and relationships with others".

"Hall (1976) highlights the importance of context in culture. Hall has explained that how understanding a context can make a difference in giving meaning to a problem". Thus cultural context has also an effect on problem definition, as problem definition depends upon the perception of people and culture shapes this perception. In any research problem definition plays the central role. "The goal is to become aware of one's own cultural lenses and the way they effect our perception of the world around us" (Saleh, 2005). In an organization management has to deal with innumerable problems on daily life. If a problem is defined properly only then the management can find workable solution for it. Thus, in short it can be said that culture is the base line for management activities in organizations. 


\section{Compensation Practices and Cultural Context}

One such example of management is compensation practices. Although many HR practices help develop the people's perception about the organization's culture but compensation systems are amongst the most important and dominant ones. Compensation systems are the observable attributes of an organization's culture and serve as indicators of the less observable attributes that prevail in the organization. Compensation systems can act as signals to potential candidates of the organizational culture. "Rynes (1987, p.190) proposed that "compensation systems are capable of attracting (or repelling) the right kind of people because they communicate so much about an organization's philosophy, values, and practices "(Kuhn, 2005). It must be understood that the compensation system of an organization do convey some message to the people about the organizational culture but it this does not amount to the fact that the entire organizational culture can be perceived on the dimension of compensation systems only, there are several other HR practices that constitute organizational culture.

Compensation policies and practices mainly originated in the west because of their rigorous research in this field and also due to their earlier business dominance world wide. Even the concept of organization also originated in this part of the world with the introduction of industrialization. Compensation practices are the cornerstone of employee motivation at work place. These practices must run parallel to organizational culture, in order to uphold its values that lead towards goal achievement. In different cultures the people's moods of motivation also changes in accordance to the prevalent cultural context. In some cultures people give value to intrinsic rewards over extrinsic rewards. This preference is partly due to an individual's perception which defines their level and context of satisfaction but partly due to the influence of cultural context which has an affect on employee's cognitive framework. Culture however, stressed by Fisher and Bibo (1998) has an impact on performance and satisfaction level of the subordinates. For example the perception of equity and expectancy based on the two traditional theories of motivation changes its meaning with the cultural context.

Further, this perception has an important implication on the organizational reward system. According to Kuhn (2009) in some cultures personal bonds and informal contracts have more value than formal contracts. This is true for eastern cultures which are highcontext. But in the western culture meticulous wording of contracts in written form is viewed as paramount. Kuhn (2009) conducted research to prove that there exists some relationship between organizational culture and compensation systems of firms. He views the relationship between culture and compensation the other way round. According to the author compensation systems plays a critical role in shaping organizational culture. It affects the employee motivation level and performance and upholds the organizational values. Compensation systems are also believed to affect culture (as well as performance) through self-selection of organizational members. Thus, we can say, that culture and compensation both have an impact on each other. Whichever acts, the other will react and it goes on like a cat and mouse race.

Long and Shields (2010) have discussed the firm-level characteristics which, have an impact on the pay system of an organization. For example firm size, industry sector, and employment status. Larger firms have a greater propensity for adopting all types of pay for performance plans; this is because of the number of employees due to which the fixed costs of plan development and administration can be spread across all employees making it feasible to adopt such plan. The second variable is the industrial sector within which a firm operates. The nature of industry and the industrial sector norms also have an impact on compensation systems and structures. The industrial sector standards usually become the company's standards in compensation management with slight variation. Again reward management can be affected 
by employment status. Since cash recognition plans are usually applied to permanent employees, therefore, part timers and casual employees, because of their non eligibility to cash awards lose motivation. These non-permanent or contingent employees can be motivated through the use of non-cash rewards at work place.

\section{Pay for Performance and Cultural Context}

Pay for performance also has links with the recruitment strategies of employees in organizations. The organizations that offer pay for performance schemes attract those potential employees who are hard working and ready to exert higher levels of effort in order to get more from the organization in form of rewards, thus providing an image of organizational culture to the outsiders. According to Kuhn (2009) individuals will be attracted to organizations which they perceive to be compatible with their moods in terms of its culture. "Lawler and Jenkinson (1992, p. 1016) further pointed out that collective and individual performancebased pay and organizational culture may effect. Performance-based pay has been termed the 'most obvious link' between pay system practice and organizational culture "(Kuhn, 2009).

In high context culture or collectivism, people have more cohesion in their groups, therefore reward system and incentive regime should be designed as such that takes into consideration and is based on group performances. In low context cultures or individualism, people prefer independence and individual rewards therefore, incentive regime should incorporate schemes such as pay for performance, merit pay etc. Contrary to this statement Kuhn (2009) argues that even in collectivist cultures people like to have their pay based on equity concept rather than equality bases. The point made by Kuhn (2009) thus breaks the myth that individual performance schemes nurture a negative affect on the organizational culture. The success of any scheme depends on its meticulous design and proper implementation.

Kuhn (2009) states that pay for performance can be studied empirically in organizational cultural context with the help of these two cultural constructs, i.e., individualism and collectivism. Organizational individualism depicts that employees are encouraged by recognition of their unique talent and potentials and inter employee competition is an acceptable norm. Organizational collectivism on the other hand upholds the attributes of team work. The author argues that advertising bonuses based on individual performance will imprint an individualistic culture on the people's mind about the organizational culture. especially if the bonuses are based on an implied ranking of the employees' performance rather than on a system that does not suggest a zero-sum competition for rewards (such as bonuses based on achieving particular targets or for skill acquisition). On the contrary, firm advertising bonuses on team or organizational performance will portray a collectivist culture of that firm.

The equity concept basically refers to individual pay for performance plans. Therefore, this is to emphasize the fact that in collectivist cultures pay for performance should not be restricted to only group productivity but there are other options that can also be considered in adopting pay for performance pay scheme.

\section{Cultural Context of Pakistan}

The sub-continent had been under British rule for over hundred years. Although colonialism ended in the sub-continent a long time ago but the Brits left their legacy behind, affecting all parts of cultural components of the sub-continent. Pakistan being a part and parcel of sub-continent was also affected by this colonialism and it was reflected in its culture, especially the administrative culture of the country. The region in still under the influence 
of British culture but its strength has weakened to a greater extent and is now restricted to administrative machinery. To depict the culture of Pakistan in more detail we can borrow the cultural dimensions proposed by Hofstede (1980). "Hofstede's (1980) cultural dimensions serve well to explain the differences of values of different countries" (Routamaa, Hautala $\&$ Mohsin 2007). These dimensions include: uncertainty avoidance, power distance, individualism/ collectivism, and masculinity/femininity. Hofstede carried out a research and rated 53 countries on indices for each dimension, normalized to values (usually) of 0 to 100 . His research has revealed that Pakistan scored 55, 70, 14, 50 and 0 on the dimensions of power distance, uncertainty avoidance, individualism, masculinity and Confucian dynamics. This rating gives us a clear idea about the cultural context of Pakistan. Using five cultural dimensions an overall picture of the cultural context of Pakistan can be obtained, which are: power distance, uncertainty avoidance, collectivist vs. individualist, masculinity/femininity, high and low context culture. The cultural dimension of Confucian dynamism will not be discussed in the context of Pakistani culture because the term is totally unfamiliar in this region and this can be validated from the cross-cultural study of Hofstede, where the score on this dimension is 0 .

Pakistan has a high power distance culture. Power distribution shows great variations in all the sectors of the society. People lie on extreme poles. Power is concentrated in the hands of few who are all powerful. They take all important decisions without consulting the masses. The people being stuck in routine issues don't really bother or care much either. Pakistani society has therefore a huge differential gap in terms of power distribution. If we measure Pakistan on uncertainty avoidance dimension, it seems to be on the lower end on the continuum. Due to flaws in the planning process and extreme volatile conditions, nothing can be predicted with certainty. The people seem to have accepted this fact as a part of their lives and are living comfortably with it. Again, Pakistan has a collectivist culture. At the root of this collectivist culture is the age old joint family system in our society. People like to share things with each other and prefer group work. They prefer relationships over work. In fact, its cultural context reflects all the characteristics of a collectivist culture. This fact has also been endorsed by different researchers who have conducted studies on cross cultural contexts of countries around the world. One such study is that of Hofstede. The result of this study shows that Pakistan is rated 14 on the dimension of individualism on a scale from 0 to 100 . Further, Vesa, et al (2008) have also confirmed this fact by stating that " Pakistan and Arab economies represent more masculine and collective countries compared with feminine and individual North Europe, and, presumably, there are also some systematic differences in values."

Applying the fourth dimension of masculinity/femininity, it is very obvious that Pakistan has highly masculine culture. It is a male dominated society where females are given subsidiary roles in the society and considered as second class citizens compared to their male counterpart. Besides, these cultural dimensions another important dimension is high and low context culture. This dimension has already been explained at length and breadth. Looking at the discussion given under high and low context, Pakistan falls under the definition of high context culture as the cultural context of Pakistan on this dimension seems to be more skewed towards high context and collectivism.

It is due to this fact that people in Pakistan do not take time management as a serious business. This is true of high context culture. People in Pakistan have all the time in the world for all other activities except work. Work is the last thing they have on their minds. A similar culture exists in organizations. In low context cultures people working in organizations are paid for the work they do and not just the time they spend at the work place. According to Fisher and Bibo (1998) time is taken as synonymous to money in low context culture. Furthermore, employees are focused on a single agenda while at work. In high-context 
cultures where relationship is of more importance the employee comes first and then comes work but in low context cultures where the people have lose bonds it is the reverse.

\section{References}

Fontaine, R., \& Richardson, S. (2003) Cross-cultural research in Malaysia; Cross Cultural Management. An International Journal, Vol. 10 (2) 75: 89

Fisher, G.B., \& Bibo, M. (1998) No Leadership without Representation. International Journal of Organizational Behavior, 6(2): 307-319

Goman, C.K, Communicating across Cultures,

Hofstede, G. (1980). Culture's consequences: International differences in work-related values. Beverly Hills, CA: Sage Publications.

Johnson, N.B, \& Droege. S. (2004) Reflections on the Generalization of Agency Theory: Cross-Cultural Considerations. Human Resource Management Review 14: 325-335, Science Direct, ELSEVIER

Long, R. J, \& Shields, J. L. (2010) from pay to praise? Non-cash employee recognition in Canadian and Australian firms, The International Journal of Human Resource Management, 21(8) 1145:1172

Kuhn, Kristine M. (2009) 'Compensation as a signal of organizational culture: the effects of advertising individual or collective incentives'. The International Journal of Human Resource Management, 20 (7) 1634:1648, Publisher Routledge, Informa Ltd Registered in England and Wales.

LeBaron, M. (2003), Communication Tools for Understanding Cultural Differences (taken from Donal Carbaugh, Intercultural Theory [on-line] Available from ; Internet)

LeBaron. M \& Bruce G. (1993) Conflict and Culture: Research in Five Communities in British Columbia, Canada. Victoria: University of Victoria Institute for Dispute Resolution

Mustafa, M..S ,Bhagat, R..S, \& Babakus, E.A. (2005) Cross-Cultural Investigation of Polychronicity: A Study of Organizations in Three Countries. Indiana University-Purdue University Fort Wayne, \& University of Memphis (TN)

Oxford Concise Dictionary, 2005, Oxford University Press, 7th Edition.

Ouchi, William G. and Alfred M. Jaeger 1978. Social Structure and Organization. In: Environments and Organizations, Marshall W. Meyer (ed.). San Francisco: Jossey-Bass

Ogden, H.J. (2010) Age, Gender and Country Effects on Cultural Dimensions in Canada and China, Sobey School of Business, Saint Mary's University, Halifax, Canada Shen Cheng, Business School, Zhongnan University of Economics and Law, Wuhan, China Hofstede, Geert H. (1980), Culture's Consequences: International Differences in Work-Related Values, Beverly Hills: Sage Publication

Reeder, B , Conflict Research Consortium, LeBaron, M. (2003), Book Summary of Bridging Cultural Conflicts: A New Approach for a Changing World, Jossey-Bass, San Francisco, CA 
Sayým, K. Z. (2010) Pushed or pulled? Transfer of reward management policies in MNCs, The International Journal of Human Resource Management, 21(14) 2631 : 2658, Routledge

Salleh, L. M. (2005) High/Low context communication: The Malaysian Malay Style. Proceedings of the 2005 Association for Business Communication Annual Convention

Sokoya, S.K. (1998). Hofstede's Cultural Dimensions of Value Orientation of Nigerian Managers: Implication of Management Practices . International Journal of Values based Management 2: 225-235, Khover Academic Publishers, printed in Neitherlands

Taylor, J. (2005) 'The next generation of workers in Australia: their views on organizations,work and rewards'. The International Journal of Human Resource Management, 16 (10) 1919 :1933, Routledge

Vesa R, V., \& Tiina M. \& Hautala, T.M.(2008) Understanding Cultural Differences; The Values in a Cross-Cultural Context. International Review of Business Research Papers, 4 (5): $129-13$

Wheatley, M. .J. (2009) Leader Does as Culture is? Global Business Leadership.Adapted from Victor, D.A. (1992). International Business Communication, Harper Collins, New York.

Don't manage culture, celebrate it as a source of different ideas.

- Ashok Soota, President of Wipro (1984-1999) 